\title{
Adierazgarritasun zantzuak euskal gazteen txatetan ;)
}

\author{
Elixabete Perez Gaztelu eta Esther Zulaika Ijurko* \\ Deustuko Unibertsitatea
}

\section{(Signs of expressiveness in chats by Basque speaking young users)}

DOI: $10.1387 /$ gogoa.15632

\begin{abstract}
Meaningful examples of signs of expressive language in chat messages which are interesting from different points of view have been compiled in this study. It is demonstrated that Basque youth are creating their own code for Internet communication in the Basque language. Some components of this type of function (which are used together with other types of functions) were also gathered. Said components are linguistic resources to convey expressiveness (lexical, morphological, palatalization...) and graphic resources which have become almost compulsory in chat communication (through a combination of symbols, and emoticons).
\end{abstract}

Keywords: chats, expressive language, youth language (verbal and written), informal variety, types of functions.

\section{Helburua}

Txat moduko elkarrizketa mintzidatziak (Perez Gaztelu \& Zulaika 2014b) komunikazio esparru aukerakoak dira (euskal) gazte-nerabeen komunikatzeko moduak aztertzeko.

\footnotetext{
* Deustuko Unibertsitateko Komunikazioko ikertaldearen ildoan kokatzekoa da ikerketa hau. Eskerrak eman nahi dizkiegu Eneritz Albizu ikasleari, Yoseba Peña adiskide informatikariari, eta Haizea ilobari aztergaia eskuratzeko zubilana egiteagatik; zubi ezean gure honetara iristeko modurik ez genuen izango.
} 
Lan honetan txatetako mezuetako alderdi bat aztertuko dugu; adierazgarritasuna ${ }^{1}$. Erakutsiko dugu euskal gazteak bere kodea eratzen ari direla Interneteko barrutian euskaraz komunikatuta. Era berean, jasoko ditugu aldaera funtzional honen (euskal hiztun gazteok beste aldaera funtzional batzuekin batean menderatzen duten aldaera honen) osagaietako batzuk: adierazgarritasuna kanporatzeko hizkuntzazko baliabideak eta txatetako komunikazioan ia-ia ezinbestekoak diren baliabide grafikoak.

\section{Txatak ikertzeko arrazoiak}

Txat $^{2}$ direlakoen ikerketa alde askotatik da erakargarria. Batetik, Ordenagailu Bidezko Elkarrizketa (OBE) (CMC ing. Computer-Mediated Conversation, Herring 1996) izateak berezitasunak ematen dizkio hiztunek auzolanean eraikitzen duten diskurtsoari (Torres 1999). Gazte izan ez izan, OBE izateak mugarritzen du hiztunen arteko komunikatzeko moduaren forma (nola idatzi) eta gaia (zertaz idatzi).

Eskakizun akademikoak albo batera utzita, gazteek lagunartean solasean aritzeko idazten dute, eta horretarako IKTez eta Internetez baliatzen dira. Esan daiteke lagunarteko komunikazio idatzia Internet bidez besterik ez dutela bideratzen. Ezin baiezta daiteke, baina, kontrakoa. Internet bidezko komunikazio (idatzian) beste komunikazio modu, solaskideen arteko harreman mota, testu mota askok dute bere lekua (gizarte-sareetako mezu publikoak, blogak, zerrendak, mezu elektronikoak...) (Zamorano et al. 2004). Hala ere, ezin pentsatuzkoa da gazteen lagunarteko komunikazio idatzia IKT eta Internet aurrean izan gabe. Eta hementxe du kokalekua, hain zuzen, ikergaiak.

Gazteen komunikatzeko modu honetan, harremanen tratuaren arabera (Watzlawick 1967), solaslagunak parekideak dira, ez dago gizarte mailako alderik beren artean (Escandell 2005), komunikazio egoera informala da eta hiztunen komunikatzeko helburua ia beti ludikoa (Tusón 1996) da.

Horrek dakar idazkeran ere gazte izatearen ezaugarriak azpimarratu behar izatea; alegia, arauei muzin egitea bai ortografian —idazkeraren forma bera

\footnotetext{
1 Oñederraren (1990) adierazgarri(tasuna)ren ildoan. Euskaltermen bai adierazgarri (palatalizazio adierazgarri) bai adierazkor daude jasoak (azentu adierazkor, interjekzio adierazkor). -GARRI eta -(K)OR atzizkien arteko aspaldi samarreko «lehiaren» erakusgarria bide da tartean (Azkarate 1990, 1993, Oyharçabal 2001). Elhuyarrek arestiko bien ondoan, hitz-elkarketarako espresio osagaia ere proposatzen du. Zehazki hiztegiak adierazkor besterik ez du itzultzen, baina función expresiva itzultzeko adierazpen-funtzio darabil. Euskaltzaindiaren Literatura hiztegian funtzio adierazkorra izendatu dute geroxeago aipatuko dugun Jakobsonena.

2 Ingelesetik hartu dute hitz hau inguruko hizkuntzek. Hiztegi Batuak ez du (oraingoz?) jaso, baina Sareko euskal hiztegiek (Sare Sozialen Hiztegiak barne) forma hau darabiltenez gero guk ere txat darabilgu.
} 
«iraultzailea» da-, bai hautu lexikoan (hiztegi adierazgarria), bai elkarri zuzentzeko bokatibo edo deikietan, besteak beste.

Txatgileen mezuetan garbi nabari daiteke hizkuntzaren eginkizun autoespresiboa (Tusón 1996), hiztunaren emozioak kanporatzeko bitartekoa, «hemen nago», «inguruak niregan eragina du» adierazi beste helbururik ez duena, alegia. Arrazoiak zeharo mendean duen hizkuntzaren erabilera, eta informazioa ematea helburu duen eginkizunaren zeharo beste muturrekoa.

Funtzio hori guztiz lotua dago txatetan sintoniaren, harremanaren, funtzioarekin. Beharrezkoak ez diren mezuak, baina hutsuneak betetzeko, hiztunen arteko distantzia laburtzeko ezinbestekoak direnak ekoizten dituzte txatgileek. Tusónek (1996: 73) —txatak sortu baino lehen ere- eginkizun honetan kokatzen ditu, hain zuzen, gazteek darabiltzaten «klitxe» asko (tío, no te enrolles, ¿Te quieres quedar conmigo?, ¿nos abrimos?...), bere hitzez esateko, «apokaliptikoentzat» adierazpen-urritasunaren seinale garbiak direnak. «Apokaliptikoentzat» ez bezala, Tusónentzat esapide horiek harremanak egiteko osagaiak dira, oinarrizko bitartekoak belaunaldi berekoen artean taldearen sintonia antolatzeko.

Modu klasikoan esanda (Bühler, Jakobson), txatgileek jolas-solasean darabilten hizkuntza batik bat funtzio adierazkorra ${ }^{3}$, espresiboa (igorle den NIaren, agerbide berariazkoa), funtzio konatibo edo deitze funtzioa (hartzaile den solaslagunari dei egitekoa, hurko horrengan eragin nahi izatekoa) eta fatikoa (bitartekoa, ukibidea zabalik dagoela adieraztekoa) betetzen dituela darabilte. Funtzio poetikoarekin ere lot daitezke txat-sortzaileen ekoizpen batzuk, mezua bera arretagunea da eta. Hitz-jolasak asmo sortzailearen islatzat har daitezke.

\section{Gaboooon kaskamelon!!! :-}

Bestetik, elkarrizketa da txata (hizketa-trukea ia-ia aldi berean gauzatzen da), baina solaslagunak aurrez aurre egon gabe -alegia, elkar entzun, ikusi, sumatu gabe-, hortaz, komunikazio «bitartekoduna» da (Rodrigo Alsina 1989), eta horrek idazteko moduan ere ondorioak dakartza, pertsona arteko aurrez aurreko komunikazioan horren garrantzitsua den osagai paralinguistikoa eta komunikazioan horren erabakigarriak diren hizkuntzaz kanpoko osagaiak idatziz nolabait adierazi beharko edo/eta nahiko baitituzte hiztun idazleek (Perez Gaztelu \& Zulaika 2014a, 2014b).

Agerian dago, hortaz, txatak oso behatoki egokiak direla hamaika aztergai eta jakintzatarako: behialako (Platon-Sokratesen Fedro-tik hasita? (Vintró 2002)) ahozko adierazpidearen eta idatziaren arteko harreman gorabeheratsua, gazteen hizkeren ezaugarriak (Amonarriz 2008), hizkuntza aldaera eta

\footnotetext{
3 Euskaltzaindiaren Literatura Hiztegitik hartu ditugu Jakobsonen funtzioen izenak.
} 
erregistroak, hizkuntza-sortzailetasuna... Alegia, Fonetika-Fonologiak, Semantika, Pragmatika, Soziolinguistika, Semiologia edo Semiotika, Komunikazioaren Teoria... Ikuspegi diziplinartekoa lagungarria da guztiz txatak ikertzeko.

\section{Txatak euskaraz eta adierazgarritasuna}

Euskal hiztun gazte-nerabeek ere «gizarte-sare» deiturikoetako txatetan topatzen dute, hain justu, beste komunikazio esparru idatzi batzuetan ez duten askatasuna adierazgarritasunez, bizi-bizi, komunikatzeko. Batik bat hizkuntza bidez bideratu eta adierazten den ezaupidearekin —osagai kognitiboari doakionarekin - batean, beste gisa bateko adierazkizunak (estimua, zirrara, sentimenduak...) eta beste era bateko informazioa kanporatzeko (eta hartzeko) bitartekoak dira txatak euskal gazte-nerabeentzat.

Lan honetan adierazgarritasuna testuratzeko modu batzuk aztertuko ditugu. Horretarako kontuan hartuko ditugu txatetako mezuetako osagai linguistikoa (hobeto esan, osagai horretako alderdi batzuk: lexikoa, morfologia, bustidura...) eta aurrez aurreko gizaki arteko ahozko elkarrizketetan hizkuntzazkoak ez diren osagaien pareko beste elementu batzuk.

Azkenok direla eta, aztertuko dugu nola adierazten duten idatzita bai aurrez aurreko komunikazioko informazio paralinguistikoari (baliabide suprasegmentalei) dagokiona —ahotsaren bitartez elementu linguistikoekin batean kanporatzen duguna hizketa ekoitzi-hartzean, soinu-kanporatze eta jasotzean: bolumena, doinua, intentsitatea, etenak...-, bai ez ahozkoa ez hizkuntzazkoa ez den giza gorputz osoaren informazioari dagokiona. Alegia, alderdi kinesikoa, keinu bidezkoa, eskuen, besoen mugimenduak, begitartea... Komunikazioan informazio-emailea den, baina hiztunak oharkabean kanporatzen duen (baina txatetan berariaz adierazi nahi den —eta hartzaileak hartzen duen-) informazio «letraldatu» eta/edo «itxuraldatua» ere jasotzekoa da. Labur esan, bitarteko hizkuntzazkoak izan ez izan, txatetako mezuetako adierazgarritasunaren adierazpen eta aztarna batzuk aztertuko ditugu.

Hori egin ahal izateko, bistan da, mezuak gatzatzeko darabiltzaten kodeak aztertu beharko dira. Izan ere, Internet bidezko joan-etorri laster eta bizi horietan trukatzen dituzten mezuetan kode bat baino gehiago darabilte hiztunek. OBEn idatziak izaki, komunikatzeko modu honek parte-hartzaileei hainbat gaitasun eta ezaupideren jabe izatea eskatzen die, hezkuntzasisteman nahiz gizarteko bestelako era arauturen batean irakasten-ikasten ez diren gaitasun eta ezaupideak, Interneteko sarbidea duen gailuaren erabileratik bertatik, teklatuaren erabileratik bertatik hasita.

Aztergai dugun komunikatzeko kodea euskal gazteen artean eraiki eta erabilia izateak badu bere interesa. Gazteen hizkuntza-erabilera, berez, sor- 
tzailea da. Gure hiztun berri-emaileak ${ }^{4}$ gazteak dira eta euskaldunak dira eta euskaraz eratzen dituzte beren arteko elkarrizketak. Lagunartekoak dira elkarrizketa idatziok, kideen artekoak, askotan helburu ludikoa besterik ez dutenak. Hezkuntza-sisteman ikasi duten idazteko kode arautuak ez die erabat balio komunikazio saio eta harreman hauetarako. Areago, gazteen hizkuntza-erabilera sortzaileari dagokio, hein batean, arau akademikoen mendeko ez izatea, arauei muzin egitea, arau-haustea, hain zuzen, taldearen nortasunaren (sintonia bilatu nahi izatearen, Tusón 1996) bereizgarria izan daiteke eta. Gure azterketan euskal gazteen OBEri, «kode-eraikitzeari» ere begiratu beharko diogu.

Euskal gazteen euskara batu lagunarteko idatziaren ezaugarri batzuk ${ }^{5}$ ere ispila ditzake lan honek. Izan ere, gure aztergaiaren egileak ez dira lurralde berekoak, ez dute euskalki edo geolekto bera erabiltzen lagunarteko harremanetan, baina OBEn, batez ere taldean ari direnean — baldin eta beste euskalki batzuetako hiztunekin ari badira - egokitu beharrean dira besteak/besteek diskurtsoa ulertuko badute. Behatoki egokiak dira txatak egokitzapen hau aztertzeko. Gure helburua ez da «lagunarteko batu idatziaren» ezaugarriak hona biltzea eta lagina ere ez da oso handia, baina, beharbada, ildo nagusi batzuk eskuratzeko adinakoa bai.

Aitor dezagun hemen aipatu besterik ez dugula egingo gazteek (batzuek gehiago beste batzuek apenas) adierazgarritasuna lortzeko darabilten baliabide indartsu bat; Code-switching (CS) edo kode-aldaketa (eta/edo Code-mixing, kode-nahasketa) (Gardner-Chloros 2009). Orain hemen ez lantzeko arrazoia da gaiak berariazko ikerketa sakonagoa eskatzen duela eta ezin diogula eskaini merezi duen arreta.

\section{Adierazgarritasunaren aztarnak txat idatzietan}

\subsection{Laginaren ezaugarriak}

Hainbat lekutako gazte euskaldunek eskuratu dizkiguten solasaldiak dira gure laginaren oinarria, bi gizarte-saretako (Tuenti eta WhatsApp) txat idatzietan egindako elkarrizketak.

Elkarrizketon egileak 14 eta 25 urte bitarteko 47 gazte euskaldun alfabetatu dira: 32 emakumezko eta 15 gizaseme. Gure lagineko elkarrizketa guztietan emakumezkoek parte hartzen dute, edo beren artean, edo gizasemeren batekin. Oraingo corpusean ez dugu gizasemeen arteko elkarrizketarik esku-

\footnotetext{
${ }^{4}$ Geroxeago zehaztuko dugu laginaren nondik norakoa.

5 Arreta handiagoa merezi du gai honek. Orain, baina, aztergaiari dagokiona besterik ez dugu ekarriko.
} 
ratu. Aurretiaz pentsa daiteke ${ }^{6}$ horrexek oraingo ikergaian -adierazgarritasuna kanporatzeko moduan, hain zuzen- ondorioak izan ditzakeela.

16 lagun Bizkaikoak dira 7,25 nafar $^{8}, 5$ gipuzkoar $^{9}$ eta lapurtar bat (baina Bilbon bizi izan dena). 2012ko abuztuaren 1ekoa da elkarrizketa aspaldikoena (Tuentikoa) eta 2015eko apirilaren 18koa berriena (WhatsApp ${ }^{10}$ ).

Elkarrizketa gehienak geolekto bereko hiztunen artekoak dira. Baina WhatsAppeko talde bateko elkarrizketak Euskal Herriko 9 herritako neska gazteek eginak dira. Azterketarako, ondorioak eskuratzeko beharrezkoa zenean besterik ez dugu zehaztuko solaslagunaren jatorria.

Bestalde, aipatzekoa da ez dituztela hiztunok elkarrizketak nahita egin guk azter ditzagun; ohiko modu arruntean sortu dituzten elkarrizketak eskuratu dizkigute. Eskerrak eman beharrean gara, berriz ere.

\subsection{Adierazgarritasuna idatziz adierazteko bitartekoak}

Ezinezkoa da hiztun solaskideen emozio, sentimendu, barne-aldarteak, adierazgarritasuna ispilatzen duen guztia jasotzea. Ikerlan honen zeregina eta helburua da horietako batzuen adierazpen testuratuen berri ematea.

Hainbat baliabide eta bitarteko darabiltzate hiztun gazteok, baina guk bitan sailkatuko ditugu: hizkuntzazkoak eta grafikoak, nahiz batzuetan (demagun onomatopeiak, interjekzioak...) sailkatzen errazak ez izan. Mota beraren barrenean ere ikusiko dugu gertakari mota bat baino gehiago bideratzen dituela hiztunak adierazgarritasuna lortzeko.

Hemen aztertuko ez dugun arren, uste dugu aipatzekoa dela lagin honetako hiztunok —ez neskek ez mutilek— ez dutela hitanoa erabiltzen beren arteko komunikazio lagunartekoan, nahiz eta askok euskara etxean ikasi duten, familia euskaldunetan eta giro euskaldunetan hazi eta hezi diren.

\footnotetext{
${ }^{6}$ Mutil gazte batzuek ere halaxe aitortu digute. «Guk [mutilok] ez ditugu bokalak horrenbeste errepikatzen...», «guk ez dugu horrela egiten...» [-txo, -illa... atzizki txikigarriak izenari erantsi], «guk ez ditugu hitz horiek esaten» [petardi, guapi, prexioxa, potxola...].

7 Tuentikoak: Abadiño, Berriz, Bilbo, Igorre, Mallabia, Mundaka, Ondarroa, Zornotza. 14-22 urte bitarteko hiztunak. 9 emakume eta 4 gizon. 22 elkarrizketa; guztiak bizkaitarren artekoak dira.

8 Tuentikoak: Arantza, Baztan, Doneztebe, Elgorriaga, Iruñea, Leitza, Lesaka, Saldias. 15-25 urte bitartekoak. 11 emakume eta 11 gizon. 22 elkarrizketa; elkarrizketa guztiak nafarren artean.

9 Horien artean, Tuentikoak 2 emakume azpeitiar dira, 20 urtekoak. Elkarrizketak beren artean izan dituzte.

10 Hamar hiztun dira; guztiak neskak. 18-20 urte bitartekoak; unibertsitateko ikasleak guztiak. Euskal Herriko 9 herri hauetakoak: Añorga, Arizkun, Arrigorriaga, Baiona, Galdakao, Irurtzun, Oiartzun (bi hiztun), Zaldibia, Zubieta (Nafarroa). Elkarrizketa batzuk bikoteka egin dituzte. Guztiek (hamarrek) WhatsAppeko talde berean ere elkarrizketak izan dituzte. Hau ere gure esku utzi digute ikertu ahal izateko.
} 


\subsubsection{Baliabide hizkuntzazkoak}

Prozedura lexiko, morfologiko eta fonologiko-fonetikoen bitartez adierazten dituzte batez ere hiztunek beren barrena eta beren arteko harremanak. Ahozko hizketan osagai fonologiko-fonetikoa oso baliabide emankorra da hiztunen arteko harreman gertukoa adierazteko; palatalizazioa da horren seinale nabarmenetako bat. Kode mintzidatzian ere palatalizazioak isla dauka.

Askotan hitz berean prozedura guztiak —lexikoa, morfologikoa, fonologiko-fonetikoa- gorpuzten dira.

\subsubsection{LEXIKOA}

Hitz adierazkorrak ${ }^{11}$ darabiltzate solaslagunek beren arteko komunikazioan. Agerian da lagun-adiskideen arteko komunikazioa dela, eta gertutasuna, elkarrekiko konfiantza nagusi dela harremanetan.

Batez ere agurtzeko esapideetan erabiltzen dituzte hitzok, lagunen arteko harremana abiaraztean, solasaldia hasi edo/eta amaitzeko. Hitz amultsuak, goxoak erabiltzen dituzte askotan bokatibo, deiki moduan.

Mezuetako bokatibo guztiak ez dira ahozko hizkeraren ispilua. Hiztunek berek aitortu digute solaskidea aurrean edukita ez diotela zentzua bilatzen hitz hauetako batzuk behintzat erabiltzeari. Alegia, esan daiteke kode mintzidatzia izendatu duguna ez dela guztiz eta erabat esana, «mintzatua» testura eramana, besterik gabe. Txatetako kodeak «bere» hiztegi, fraseologia... dauka, eta ez dator beti bat ahozkoarekin.

Neskek beren artean honelako deigarri, bokatibo, deikiak darabiltzate elkarri zuzentzeko: bonbonzita, guapa (wapa, wapisima), guapi, maitia, monona (moñoña?), neskatila, neskatxiek, nexkak, petarda, pippol, pittina / pitxina, pitxilore, pitxurrina, polittak, politte, potxola, prexioxa, señorita, tia, txikitxu...

ola potxolaaaaa!!!! [...] mosu handi bat prexioxa!!!!!!, hello neskatxiek!!!, EEpa pipol!!, helloou neskak!!, alo alo neskatxiek!! Zln gabiz??

epa wapaa!!!!! zmz??? azkenin zer moduz juan ttire rekuperaketak????, olaia wapaaa $\mathrm{zmz}$ ? dena ondo????????????? [...] bueno wapisimaa ongi ibili ta ern muxuuk $=\mathrm{D}$

\footnotetext{
11 OEHk zehazten eta itzultzen duen bigarren adieraren arabera darabilgu adierazkor batez ere. Koldo Mitxelenaren adibide hauetako adieren ildoan. «2. Expresivo, que expresa sentimientos. [...].: Idatz dezagun, gutxienez, iñ eta ill, ñ eta ll-ren ordez, hitz adierazkor (expresif) horietakoak ez baldin badira, behintzat (-ño atzizkia daramatenak eta). MIH 101s. Lau sailetan banatzen dira hizkuntza horren hitzak [...]: (a) etxekoak, (b) sino-japonesak, (c) onomatopeia (hitz adierazkorrak), (d) arrotzak. MEIG VII 178». Letra lodia gurea da.
} 
Bizi naaaz polittaaaaak!!!, Zelaaaaaaaan txikitxuuuuu???, Atsalde on nexkak!!, Neskaaakkk, Bueno gaboon pittinaaaasss! ???????????

Zelaaaan gaztee martxaan neskaaaak???, Altxaaaaaaa neskatilee

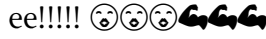

Elkarrizketak bukatzeko ere antzeko deikiak darabiltzate:

H12: metodologia etzat gustatu. Bn bueno. Zirriborroa da... Ondoloin politte. Bihar kontako nazu abr garko eune zemuz.

H2: geo difentziya eon ber du asike nunbatte eongo dia akatxak. Bihararte petarda.

H1: jajajjajjaj hoidaaaa !! bihararte! Amets goxok in

H2:bai iualmente guapiii

Biharartee bonbooonzitaaa

H1: Alazne!!! Zelan juen da operaziñue??? Ondo??? Nerbixuok pasau die??? Bueno señoritaa rekuperau zaitte bizkorr!! Muaaa

H2: bueno prexioxa eztakitt ikusikogaien elorrixon baia, bestela ondo pasau eta deittukotzut edo egongoga egunen baten bale??

H1: Paaastu gaboon polliiiit

H2: Zaiiibdu mononaaaaas [zaindu]

Erki pasaaaa

H1: Baaaardiiin txikitxuuuuu ?????????????

Aipatzekoa da neskek elkar izendatzeko ere hitz maskulinoak darabiltzatela: ombre, tio, chaval. Tusónen (1996) klitxeen eginkizuna bide dute.

Tio: Zer da haau tio..., Nei regla jetxi nau t hilla tio.., Jooo zeee ondooo tiooooo jajajajajaja, Ostin sustuamanazu tio

Txabal: Buaaa esqueee nik ez dekot ideiarik bez chavaal....

Hombre: Bayeetz ombree

Elkarrizketan parte hartzen ez duen beste emakume bat izendatzeko tipa hitza darabilte, baina ez du gaitzespen kutsurik.

Ni tipakin getu naz klasia itEitrko 45tan po settun hanaz

\footnotetext{
12 Horrela bereiziko ditugu elkarrizketa bereko hiztunak. H1, H2... sinboloek ez dute inor ordezkatzen, ez dagozkio beti hiztun berari.
} 
Mutilak (nafar mutilak) neskei honela zuzentzen zaizkie: loka, petarda, pringada (de la vida), sosita...

M113: Olaaaaaaaaiaaaaa!!! ya, goiz gan gñen etxeraaaaa!! zu zmz??? elizondon 2 egunek eee jajaja bueno SOSITA muxu bat!

M2: buffff ezdakittt nire intentziua da segitzia surf egiten, biño klasiak ez dittut artu bar ordun in barko dudana da aorratu ta erosi tabla bat nire kontura. sk zarautz da la ostiaaaa, olatuak dire oso onak ta da kriston gozamenaaa pringadilla d la vidaaa $\mathrm{k}$ no te enterassss

N: jajjajajaj bakarrik erran bar dizut gauz bat: KE PRINGAU! jajajjaja

lasai my pringy friend, te esperareeee!!!! :D

M2: pringadaaa! zmz? aspaldi ez nizula mensajerik bidaltzn jej

$\mathrm{N}$ : pringauu!!!! aitz ongi!! ta zu??

M3: joditu zait txata.. erotu de ez dakit zer dun jaja. jode itxin jatenzu obe, ez duzu garbitu barrik... a la buena bida jaja. bueno oli ligona egoin gra bertze batin mxk

$\mathrm{N}$ : baaalee!!! egongo gara ibi el rompecorazones! ondo lo in! aioo

N: Guuuaaaapoooooooohhhhhhhhhhh!!! tioooooooh gggggguuuuuuueeeeennnhhhooooo!!

M4: gelditzen gara tragoxka bet hartzeko guapika??

M5: ez in kasu petrda!!!!!!

Arestian esan bezala, harremanak hasi eta bukatzeko esapideak sintonia eraikitzeko (funtzio fatikoaren) adierazle garbiak dira.

Hitz iraingarriak, disfemistikoak, biraoak... erabiltzea gazteen hizker(ar)en ezaugarritzat jotzen da. Alde batera utzita zenbateraino den adina elementu bereizgarriena halako lexikoa erabiltzeko, gure laginean oso jokamolde desberdina sumatu dugu hiztun gazteen artean.

Batzuek, behintzat, ez dute ia batere erabili (gure emaitzak ez datoz guztiz bat Ibarra (2011: 50)-ren irizpidearekin; gure hiztun horiek apenas erabili duten «emozio-egoera edo subjektibitatea adierazteko» («gramatika expresiboko» hizkuntza forma kodetuen bitartezko (Porroche Ballesteros 2015: 191)) hitz iraingarri edo antzekorik). Halakotzat jo daitezkeen eroa, puta, tonta ez dituzte oro har iraintzeko erabili hiztunok; txantxetan erabili dituzte:

Puta lur.. Jajajaja, Tontaaaaaaaaaaa, Tonta bat zaaraaa!!!, Jajanajaja eruaa...

\footnotetext{
13 Mutiletako 1 (M1), beste mutil bat (M2)... N : Neska. Bakarra da.
} 
Beste hiztun batzuek maizago darabiltzate halako hitzak, batez ere kodenahastea tartean dela ${ }^{14}$.

jajajaj puta oly!! (con cariño) XD pos egia san nik re eztakizkit e! alere san bar diot maddiri

buuuuuuuuuuaa ke kabrona jajajajaj bixer kontaukozkuzu!

keba keba bier ikestera komo un kabron batugule lan bastante

Iraintzeko asmoarekin behin edo beste ere badarabiltzate irainak; gutxi$\tan$ oso:

jaj, pablo da pixkot kabron bai jaj,

es una puta aborta!! sin mas, ta bai liau ei die bi bider e...asi k..... asta bixer maialentxia!!

«Behe mailakotzat» («Léxico procedente de un estamento inferior», Ibarra 2008: 226), edo, nahiago bada, lexiko landugabe, arrunkeriatzat jo daitekeenaren adibideak ere jaso ditugu. Lehen multzoan jasotzera goazenak gazteen lexikokotzat jo daitezke. Asko CSen artean aztertzekoak dira:

Ze oao oso txubgua daa [txungo], zagon ultzamako jendiz beteta, petau!, flipatzen; psada, pasdaa [pasada]; tope disfrutau, atope; asako; krak; friki; nausieekin sobrauuuu; ke guai tio; porkulo, kriston pollue, txapie (BI), txapa (NA), Jajajajajaaajj besteaaa pira ??

nik eztot kaka ziriñik ein eee!!, jode, joe, kauen zozttzzz, ostia ba ezer enekiyeen.., nre klasekok dire uns sososs d cojones!!!, biaje luzia! la letxe!, Joder dago DPM! [De Puta Madre], MEKASUENLAMAAAAAAAR!!, ni [nago] de puta madre, eskerrikasko maialen puta ama mua, de kulo, joditu zait txata, da la ostiaaa...

Adierazpideari indarra ematearekin ere egon daiteke lotuta adierazgarritasuna.

Baliabide grafikoak geroago ikusiko ditugula eta, baliabide linguistikoen (lexikoaren?) artekotzat jo daiteke hitza(k) errepikatzea (Oñederrak ere (1990: 59) baliabide adierazgarrien artean aipatzen du). Izan daiteke funtzio konatiboa, hartzailearengan eragiteko helburua dela medio (mese(dez)) nahiz hitzaren esanahia, intentsitatea areagotzeko (txintxo-txintxo, goxo-goxo...).

Biali tesrue mese mese

Haizeaaa bihar txamarra mese mese meseeee

\footnotetext{
14 Arestian esan bezala, ikerketako beste aldi bateko gaia da.
} 
Atzo txintxo txintxo etxian $t$ deba afaldu nuun, hau hotza itten tzuna jiji

Yihaaahaaaaaaaiiii !!!! Gaur goxoo goxoo lolooo (-)(-)

Igorleak hartzaileari (hartzaileei) aurretik esandakoa onartzen duela, bat datorrela adierazteko balee (bokal gutxiago nahiz gehiagorekin) errepikatuta darabil; elkarrizketan aurrera egiteko, elkarrizketari eta komunikazioari laguntzeko modua $\mathrm{da}^{15}$.

\section{Bale baleee}

Bale bale lasai iya zoze itteuten ajajaj

Solaslagunak aurretik esandakoa erantzunean txertatu eta norberak osatzea ere komunikazioan laguntzeko jarrera da:

H1: Kixton politte ihintza jajaa

H2: Kixxxxtonaaa! Jajajajaj:0;

Hitzak errepikatu gabe, graduatzaileak ere eginkizun bererako erabiltzen dituzte. Gazte hauen txatetan ahozkoan ere badarabilten ostion, Kristo(re)n lexiko markatua erabili dute.

Wske ostion buwlta mandit osa jaaja, Bi nijua ostion nalera haundiyakin e

Kixton politte ihintza jajaa, da kriston gozamenaa

Hitzak laburtuta (apokopatuta) idaztea sintonia bilatu nahi izatearen bitarteko lexikotzat jo daiteke. Kideen taldearen ezaugarritzat, taldeari izaera eta nortasuna emateko bitartekotzat har daiteke.

Mintza $=$ Mintzaera eta Idazkera ikasgaiaren izena.

Ni mintza jung naiz

Trikiya $=$ trikiti musika tresna izendatzeko.

San naute abeer hola bada noiz joko zenuketen trikiya

Osea gu gea or jartzeitun trikitilarik?

Deikiak aipatu ditugu arestian, elkarrizketak hasi eta bukatzeko formuletan txertatuak. Forma laburtu grafikoak ere badarabiltza hiztun gazteok elka-

\footnotetext{
15 Barkamena eskatzeko, eskerrak emateko, desadostasuna eta beste adierazteko moduak ere badarabiltzate.
} 
rrizketa hasiera samarrean (Zer moduz?, Zelan?), amaiera aldean (Muxu(ak)), eta funtzio deigarri edo konatiboa dutela, solaslagunaren gogoan eragiteko (mesedez, kontestatu, erantzun). Maizenik darabiltzatenak dakartzagu. Esaldi, hitz laburtuok laburdura finko ez ote diren bihurtzen ari pentsa daiteke.

— «zmz (zm, zmd, zmuz)», «zln»: zer moduz, zelan. Zln bizkaitarrek darabilte batez ere.

Joe tio...ta iraid zm eo?, Zmuz atzoo?, laidaaa!!!! zmz?? ya rekuperatua, ez??, Garazi!zmd?

(BI) zu zln ibili za ba valladoliden ba?, zln eingogu

— $\ll x x », \ll \operatorname{mx}(x) »:$ muxuak.

zerbait baldin badakizu abistu, faborez. mxk!, ongi probestu!!!mxxmxmxmx, Bai lasai itzuliko dazkitzut abr prestatzen duten eta edukitzekin dena abisatuko datztok?? Mxx

— «msdz», «ms»: mesedez.

bueno juen pentsetan ta kntestau msdz, knt ms ta irakurtzen dozunien ein tok bat msdz, bueno....orduen bueltilla durengora edo?? knt ms

— «kntx», «knts(s)», «knt»: kontestatu. Adibide gehienak bizkaitarrenak dira.

(NA) kntx faborez!!

(BI) ta an ze eitteko asmue dau ? knts msdz muxu, bueno ba ainhoaa zaindu ta rekuperau arin, mosu bat...knts, sin falta danok entregau bidogu . bueno agur.knts, kntss muaaaaaak, knt ms ta irakurtzen dozunien ein tok bat msdz, 6ek inguru ondo ala ariñau??? knt mosu bat!!

— «ern»: erantzun (agerraldi bakarra).

(NA) bueno wapisimaa ongi ibili ta ern

\subsubsection{MORFOLOGIKOAK}

Atzizki txikigarriak (adierazgarriak, ñabardura-emaileak) darabiltza igorleak hartzailearekiko gertutasuna, maitasuna, estimua adierazteko. Euskal eta erdal atzizkiak darabiltzate elkarrizketako hurkoaren, solaslagunaren izenari erantsita (-txo/-txu/-txi; gaztel. -ita, -illa). Eta inoiz solaslagunak berak bere burua izendatzeko ere aukeratzen du forma hipokoristikoa (-txu: loretxu, -ita: Ihintzita...).

Ai loretxu anino animo, Aiiamaaaa haizeaaatxoo..., Maialentxu, Martintxo 
H1: Zooooooooriioooonaak aneetxuuu!!!!!

H2: Anetxikitxuuuu!!!! Zorionaaaaaaaaaaaaak!!!! Lixtooo yaa indezuuu!! $\cdots$

H3: An itaaaaaaaa!!! ZOOORIONAAAKKKK!!! Ze ndooooooo!!!-0;-)

Joe lurtxoo hau esan ta ze in ber duuut??, Maialentxi!! konektetan zaienien msn-ra inporta jatzu toke bat eittie??, Maddalentxiaa , ainhoillaa I have a notizioiaaa

Elkar izendatzeko izen-adjektiboak ere hautatzen dituzte atzizki txikigarri ñabardura-emaileen oinarri izan daitezen: giputxi, biskaitxar, neskatxiek...

Baleba eskermilee txikitxu, Zelaaaaaaaan txikitxuuuuu???

Oso aldian behin, elkarrizketatik kanpoko hirugarren pertsona (amatxo) edo objektu bat izendatzeko ere badarabiltzate atzizkiok: bueltatxo, bisittatxo, mesutxo [mezutxo]

Ni kanpoaan nauuu bankutxuuu batdaanp

Ooooooo zeee ongiiii !!! ;) niiii bikainn guztiekinn egonnn taaa denaaa bikain orainn gauzatxoo batzukk eginn taaaa listo kalistoo ! Zu klaseann ?;)

Musua izendatzeko ere atzizki txikigarria eransten diote izenari ez ezik (mosutxo bat), baita onomatopeiari ere: patxo bat, patxuu.

Euskal eratorbideko -txo, -txu, -txa atzizki txikigarriekin batera, -ita, -ito, -ico, -illa erdal atzizki txikigarriak ere badarabiltzate eta, horrela, osaeraren ikuspegitik hitz hibridoak sortu dituzte: ainhoillaa, muxito, pitxinita... Erdal hitz eratorri osoa mailegatu eta euskal sistema fonologikora egokitu dute (bonboncita $\rightarrow$ bonbonzita) kasuren batean eta, beste kasu batzuetan palatalizazioan ere aipatzekoa den erdal igurzkaria txistukari bihurtu dute (amorcito $\rightarrow$ amorxito).

Biharartee bonbooonzitaaa

Aixxx agurtuu zaituu ?? Mi amorxitooo

Muxitooooo, Patxote pitxinita Muaa

Hurrengoetan osorik mailegatu bide dituzte hiztun nafarrek erdal hitz eratorriak:

[NA] Biraaa, zemajikooo!!!!!, Bihar dt txarlita bat luzia zurkin... 
Inoiz edo behin, atzizki handigarri (adierazgarriak) ere badarabiltzate: -ote, -on (gaztelaniazkoa); kasu batean -oi euskarara egokitua ere bai: notizioiaaa.

Ale maiteño banue, bier te xamo! Ostirelearte,muxuu

Patxote pitxinitaMuaa

H1: Gora resakoon

H2: Goraaaaa resaakom baiiii ajajajajjajaa

Fiestoon!!!!! Ni joan nintzen goiz etxeraa bainaa jenteaa gelditu zan 8ak artee eta...

\subsubsection{Palatalizazioa, BUSTIDURA ${ }^{16}$}

Hizkuntzazko baliabideen artean, bustidura, palatalizazioa ere baliabide emankorra izan daiteke hiztunek beren barne aldartea ispilatzeko. Ahozko ohiko harremanetan euskalki batzuetako hiztunek soinu batzuk bustita, palatalizatuta ekoizten dituzte inguramendu fonikoak bultzatuta (asimilazio bustidura gertatzen da, Oñederra 1990: 18). Halako ahoskeran, hiztunak ez du ahoskatzeko modu hori hautatzen motibazio semantikoa dela medio. «Jasoa», «formala» ez den lagunarteko ohiko komunikazioan gauzatzen da batik bat halako ahoskera (Iverson \& Oñederra 1985).

Euskaltzaindiak «Euskara batuaren ahoskera zaindua» izeneko arauan ere maila jasoko ahoskeran, euskalkiaren arabera, aukerako uzten du ahoskera «arduragabeko» bustikuntza ahoskera zainduan ere gauzatu ahal izatea ${ }^{17}$.

Ahoskera «arduragabea» izan, «zaindua» izan, kode idatzi estandarrean ahozko palatalizazio horiek lekurik ez dute, idazkera arautua fonologikoa, ez soinu-transkribaketa, izaki.

Txat mintzidatzietako kode idatzia, esana dago, arau ortografikoetako mugetatik ihesi, soinu-transkribaketara, idazkera fonetikora hurbiltzen zaio. Eta ildo horretan, bustidurak, palatalizazioak —zeinahi motatakoak - ere bere ordezko idatzia dauka txatetan.

Era honetara, bada, bi palatalizazio motak, bai inguramendu fonetiko-fonologikoak eraginak, asimilazioz sortuak, bai bustidura adierazgarri (Oñederra

\footnotetext{
16 Oñederrak (1990) euskaraz darabiltzan bi terminoak erabiliko ditugu.

17 «VII. <il, in> letra bilkura hauek <(i)ll> eta <(i)ñ > eta (hala nola: mila milla edo mailua

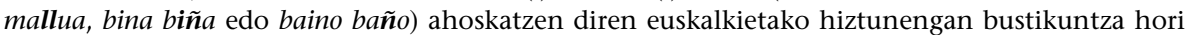
ahoskera zainduan ere egoki da (ahoskera zaindua — milla - da eta ez - miya-). Bustikuntza hori ez duten euskalkietako hiztunengan, noski, bustidurarik gabea izango da ahoskera zaindua ere (hala nola: mila mila edo mailua mailua, bina bina edo baino baino)». Letra lodiak jatorrizkoak.
} 
1990: 18) edo semantikoak bat egiten dute txatetako idazkeran, batak zein besteak solaslagunen arteko gertutasuna, hurbiltasuna, konplizitatea, naturaltasuna adierazteko bitartekotzat baitauzkate txatgileek. Palatalizazioa berariaz daramate idazkerara asko-askotan, nahiz hori ekonomiaren kontrakoa izan, letra gehiago idatzi behar dituzte eta ${ }^{18}$.

Euskalkiaren, lekuaren araberako hizkuntza aldaeraren adibideek halaxe erakusten dute, hiztunok bere ahozko adierazpide fonetikoa idazkerara daramate, nortasuna, jatorria erakustearren eta, beharbada, gainerako euskalkietako bereizkuntza agerian uztearren. Arrazoiak arrazoi, idazkera arautu estandarretik alde egiteko asmoz egiten dutela dirudi, txatetarako «formalegia» delakoan, seguruenik. Hona asimilazio bustiduraren adibide batzuk:

(Gip. Azpeitia) zergaitxik, gaxki [gaizki], axkoitin, polittek, (NA) itten [egiten], guttigo, oparittu, deittu, mugittu, konfuinttu [konfunditu], zerbatten, nittun, ttuzten [dituzten], battut [baditut], atta, norbatt; bakotxak, arratxin [arratsin], atxaldetan, aixa [aise], probexten; polliki polliki, (BI) nigaittik; bixer [biher], prexioxa, afaixe, jaixek, oparixek, armarixuen, (Gip. Oiartzun) norbattek, norbaittek, eztittut [ez ditut], biziyakin [biziarekin], miño [baina, baino], etziñen [ez zinen], settun [segituan], biyar [bihar], iruzkiña, baliyo, polittaaaaak!!!, itteko [egiteko], itteuten [egiten duten], trikiya [trikia], aleiya [alegia], iya [ia] pixun [pisuan], abixtu [abisatu], milla...

Ez dituzte, baina, hiztun berek hitz berak beti palatalizatuta idazten; idazkera ortografikoa ere badarabilte:

(-)을 ze politaaaaa!!!.

Bustidura adierazgarriaren askoz adibide gutxiago ikusi ditugu beste palatalizazio motarenak baino. Hiztun batzuek behintzat badakite aukera hori ere badutela, baina ez dute askotan jotzen soinuak palatalizatzera (edo despalatalizatzera) balio adierazgarria emateko:

Bikainn pasaaa italiann faltann botakoo zaituguu !!! (-):-(:) gozatuu ta goxatuu

Nexka, juxtu, muxuuk, goxo-goxo, lixtooo, Kixton, paxa [pasa], Ongipaxaaau [ongi pasau], atxaldian

Kasuren batean duda egin daiteke nahita aukeratu duten igurzkari sabaiaurrekoa $^{19}$ idaztea (x), teklatuan oker jo duten letra (hiru txistukari igurz-

18 Ekonomia ez da, hortaz, ziberridazkera arautzen duen hastapen bakarra.

19 Sareko Euskal Gramatikako terminologiaz baliatu gara kontsonante motak izendatzeko. 
karien teklak aski hurbil daude eta) edo hiztunak ez dituen txistukariak bereizten (esate baterako, ts/tx: atxaldian). Pixarra idatzi duen hiztunak, beharbada, forma horixe du neutrotzat eta markatutzat (adierazgarriagotzat) izan dezake pizarra.

Hitz batzuen bukaeran, hitzaren esanahia «goxatzeko» igurzkari sabaiaurreko ahoskabea [x] eransten diote batzuetan: $A i$ interjekzioa, aienea adieraztekoa, lo(lo) (lo egin aditz-esapideko izena). Arestian aipatu dugun amorcito amorxito bihurtua ere hemen aipatzekoa da.

Aixxx agurtuu zaituu ?? Mi amorxitooo

$\boldsymbol{G}_{0} \boldsymbol{G}_{0} \boldsymbol{G}_{0} \boldsymbol{G}_{0} \boldsymbol{G}_{0}$ oraiinn geldetukoo dut aberrr noizzz ditudann busakk Aix Aix aixx ;)

Lolitox nijua bale? Jakin nahi nun iya zrmuz ziñen

\section{A loloss}

Onomatopeiak, interjekzioak... esanahi adierazgarria adierazteko prozedurazko elementuak (Parroche Ballesteros 2015: 192).

Txatgileok oso maiz jotzen dute baliabide hauetara adierazgarritasuna kanporatzeko. Gehienetan igorlearen emozioen, barrengo egoeraren adierazpenak dira. Interjekzioez baliatzen dira txatgileak adierazpen horietan, hainbatetan onomatopeiez lagunduta. Adibide batzuk besterik ez ditugu jasoko, oso luze joko luke eta erabili dituzten guztiak hona ekartzeak.

Muxua adierazteko:

pa, Patxote, Muaa.

Eta Iparraldeko hiztunak:

Potttt (2):-(2):- (emotikoiak lagunduta)

Adostasuna:

bo, okei, Okey, okei perfekt, bale!!!, pos baii, ados!!!, perfekto!, klaro baietz!!!!, fijooo!!!

Desadostasuna, kexua:

jo, ez ez ez!!!!!

Barrea:

Jajajaja, Uajajaja 
Poza:

bua gaur berrriz ke buena

Tristura, kezka:

bua urrengo astin amama operatzebe

Harridura:

aiba!, ohhhh

Desira, nahia:

hori goguk!!

Inoren arreta bereganatzeko:

eiii

Ezer gustukoa dela adierazteko:

ze enbidiaaa!!!

ze gozadaaa!!!!!!

hori suertia!

Hasierako eta amaierako agurrak adierazteko:

apaaaaa olaia!!!! aspaldikoo!!!

geroarteeeeeeee!

bnga, eskerrikasko ta ongi izan!

benga, muxu haundia!!!

Lehen esan bezala, adierazgarritasunaren seinale nabarmena da hiztun batzuen (ez guztien) kode-nahastea (CS). Lurralde, egoera soziolinguistiko batzuetako hiztun batzuek, apika, CS daukate, hain zuzen, hizkuntzazko baliabideetakotzat (baliabide estilistikoetakotzat).

yaaaaa!! egia da!! joeeee muxo pringau pero bira el aitor!!jajajjaj

imaginatzen nun bino bueno, ni ez nintzn atrako erez. iñautiak arte aguantatuko duzu besta in gabe?? lo dudo mucho... xcierto ez dakit enteratu zaren ze izan zen duela haunitz, nai natzun erran en persona bino ya kasi ez gara ikusten, lorea ta nik moztu ginun, sin mas jakiteko. 


\subsubsection{Baliabide grafikoak}

Idazkailu elektronikoek, tekleatuek denon eskura jartzen dituzten kodeak, ikurrak, irudiak txatgileentzat bitarteko erabilgarriak dira ispilatzeko bai beren barrena, sentimenduak, bai irakurle(ar)engan sortu nahi dituztenak. Mezua interpretatzeko iradokizunen adierazleak ere izan daitezke irudiok, mezuaren osagai hitzezkoaren aringarriak, kontrako esanahiaren iradokitzaileak; txantxa dela ulertarazteko seinaleak... Gailuek gero eta aukera zabalagoa eskaintzen diote igorleari azaleratu nahi duen dena delakoa irudiz azaleratzeko.

Oro har, egina dagoen irudi bat pantailan txertatzea errazagoa eta lasterragoa da (baldin eta erabiltzailea «ziber-alfabetatua» badago) ikur konbinazioren bat egin behar izatea baino. Irudietarako bilakabidea garbi atzeman daiteke txat zaharrenak (Tuenti aplikaziokoak) eta berrienak (WhatsApp aplikaziokoak) erkatuta. Konparatzekoa litzateke urte gutxiren buruan nola joan den ugaritzen ikono-sinboloen aukera. Gainera, ikur-konbinazioak irudika ez dezakeen makina bat irudi erabil daitezke egun elkarrizketa (eta mezu) elektronikoetan: begitarte eta keinu era guztietako aurpegiak ez ezik, txalo joka dauden eskuak, garaipenaren sinbolo bi behatz tente dituena; indarra, sasoia adierazten duen beso gihartsua, zoriona (eta poza) adierazteko etxafuegoak; musika notak, hitzak kantu batekoak direla adierazteko, bihotzak, garagardopitxarrak topa egiten, dantzariak, etxeak, gailuak... Ohituraren poderioz bereganatzen du erabiltzaileak gailuak zer irudi eskaintzen dituen, non bila ditzakeen eta mezuetan txertatzea non komeni den.

Lehengai linguistikoa ez izateak errazten du gisa honetako komunikazioa: ez dago ez hizkuntza jakin baten ez euskalki edo gisa bateko edo besteko aldaeraren arrastorik. Hizkuntzan oinarritzen ez den bestelako kode sinboliko-ikonikoa konpartitzen dute solaslagunek: nolabait esan, ideograma- edo piktograma-kodea. Hizkuntza jakin baten mendekoa ez izateak, artikulazio bikoitzean oinarrituta ez egoteak, unibertsalagoa egiten du.

Baliabide nagusiak dira, batetik, alfabetoko ikur berak: letrak —letra larriak, letra xeheak - eta bestelako ikur ortografikoak (harridura eta galdera markak batik bat), puntuazio ikurrak (puntuak, esate baterako). Konbinatu ere egiten dituzte letrak eta markak, esate baterako, hitzari, adierazpideari indar gehiago emateko.

Bestetik, berriz, irudiek ere bere lekua dute mezuotan. Batzuetan gailu elektronikoek eskaintzen dituzten emotikoien zerrendetatik aukeratzen dute adierazi nahi duten horixe adierazteko, bestetzuetan konbinazioak egiten dituzte letra (larriak batez ere), puntuazio ikurrak (puntu eta koma, bi puntuak, dela puntuazio ikurrak eta parentesiak) konbinatuz (guk lan honen izenburuan erabili dugun ;), adibidez). Matematiketako ikurrak ere erabiltzen dituzte: berdintasuna adieraztekoa, handiago edo txikiagoa adierazteko ikurra, zenbakiak... 


\subsubsection{LETRAK, PUNTUAZIO MARKAK}

Igorleak hartzaileari letren tamainaren, errepikatzearen bitartez adierazi nahi dio, nolabait, nola ahoskatuko lukeen hitza. Alde honetatik, esan daiteke osagai paralinguistikoaren gauzatze grafikoa dela: intentsitatea, garrasiak, isiltasuna idatzita adierazteko modua.

Letra larriak. Oso gutxitan erabiltzen dituzte, oro har, txatgileek. Kode honetan letra larriek beste balio bat dute. Arau ortografikoetan ez bezala (izen bereziak ere letra xehez idazten dituzte), letra larriek hitzari, mezuari garrantzia, indarra, intentsitatea, bolumena ematen diote. Baliabide paralinguistikoaren parekoa da, hortaz, letra larriak idaztea.

MEKASUENLAMAAAAAAAR!!, ZORIONAK!!!!!!!!!!!, EJEM EJEM!!!!!!!!, ZE MOZKORRAAA, badakizu zeintzuk diren LAS CONSECUENCIAS., IRAKURRI!!!! eske Ke InUTIL ESS::, Jun esaten DANOK zozer , Bueno sin+ animetan bazara komentau eta «»TXANTXARAN»» ibilitte bueltatxo bat ein geinke!!, ESKERRIKASKO AKORDETIARREN!!,

H1: Biharko ba al dau latibeko lanik???

H2: EZZ

Letra errepikatuak: xeheak eta larriak. Agurretan, bukaerako mezuen azken hitzetan askotan errepikatzen dituzte letrak, bokalak eta kontsonanteak. Ez dirudi helburua indartzea denik. Baliteke agurra dela azpimarratzeko jotzea errepikatzera, hain justu.

Kaixooo, joodeeee, Aioooo, Loreeetxuuuu, Baaaaiii, Pittinaaaaaa, Loreeee, Oooooooook, aniiimo ganbaaarraaaa,

muxuuuu, Eztut iñolaz eree berdinee ineen eeh!, Antzii zait sekooo, Eztuuut iiin jaaaa, behi zorueekk; dirurikk

mxkkk; mxkkkkkk; muxuuxxxx; barrrrrkatu;

larunbatin kristoooooon besta!!, Jaionekiin ta afaldikoooot, Asike pastuu gerooo hemendiik

Era berean, maiz, letra errepikatuaren ondoan, hurren aipatuko ditugun harridura (eta galdera) markak ere errepikatzen dituzte.

hoidaaaaa !!, berdiiiiinnnn !!, ezzzzz!!; aunitzzzzzz!!!; batttt!!!!, ZOOORIONAAAKKKK!!!, ZORIONAKK BA ANETXUU!!, olaiaaa!!!!, kasoooooooooooooooo, eeee???, baleee!!, txopue ikusi ta gero afaldu katxinbie estrenau ta ba JUERGAA!!!!

Hiztunetako batzuek bere burua izendatzeko ere azken bokala errepikatzen dute: Maddaleeen, Luuur, Loretxuuu. 
Harridura, galdera marka errepikatuak

Gero han geldituko zariee ikasten??, Nun zare???, Zelaaaan gaztee martxaan neskaaaak???, Beneetaaaaan???, Inposiblea dala???

Arestian esana osatzearren, zehaztu behar da harridura eta galdera marka errepikatuen aurretik bokal edo kontsonante errepikatua (azkena edo azkenaurrekoa) idazten dutela ia beti.

Mileskeeer!!!, Egitaaan??, Baldakauu interbeeey??, Biher esperariko dtzuut??, Hrtu zrbaiiit!!!, Nik biher in br dut... deiriko datzut zalantzaak galdteekoo???, Biraaa,zemajikooo!!!!!, Fiestoon!!!!! Ni joan nintzen goiz etxeraa bainaa jenteaa gelditu zan 8ak artee eta... Ajjajajajajaa, Kontatko datzuuuut astelhnaiiiaaan!!!!!!??, Gaaaabooooon!!!!

Isiltasuna ere puntuazio marken bitartez adierazi beharra dute. Etenpuntuak izan ohi dira osagai paralinguistiko horren ispilua:

betikua izan zen.. poca letxe.. jajaj, eske begittu nun nere galderetan ta etziren agertzen..., bai, aber, ya itten dugun fundamento pixkot...., ai ai ai ai...... beittu ze ein daben kekak buruen!!!, aber... juen giñen olatz ainhoa eta ni, ni seguramente ena juengo.... ze zuek ze eitteko asmue daukezue??

\subsubsection{IRUDIAK}

\subsection{Puntuazio marken konbinazioa irudia sorrarazteko}

Darabilten aplikazioaren arabera, irudi gutxiago edo gehiago dauzkate eskura eta, hortaz, darabiltzate txatgileok. Tuentitik whatsApperako igarobidean (eta orain azterketatik kanpo ditugun mezu elektronikoetan beste horrenbeste) asko ugaritu da irudien aukera. Hasieran («Tuentialdian», horrela esatea badago) ortografia markak konbinatzea beste erremediorik ez zuten erabiltzaileek, batik bat igorlearen aurpegia irudikatzeko. Irudiak dauzkate orain gazte txatgileek mezuetan txertatzeko; aurpegien irudiak, eta bestelakoak ere bai, gero eta gehiago: besoak, eskuak, etxeak, janak, edariak, gisa bateko eta besteko ikono eta sinboloak.

Marken konbinazioaren bitartez igorlearen barne egoera ispilatzen duen aurpegia, begitartea irudikatzen dute. Dela poza, dela tristura, dela kezka, dela konplizitate-keinua...

Gure lagineko txatgile tuentizaleek hauek erabili dituzte batez ere:

;) begi-keinua: Jondi eztaola usteet!beinga tu;)

:) irribarrea: Zu zemuz? Bier kaftxo bai ala bai tio:)

:D barrea: jajajajaj bale bale, lasai!!! ezta yaus pasatzen! :D 
$=$ eskermile my friend!!!!!! =)

$=\mathrm{D}$ bueno wapisimaa ongi ibili ta ern muxuuk $=\mathrm{D}$

XD barre handia: ai iñaki iñaki... denak zoriontzen ai dire ta ni enaiz guttigo zan barko, ez? xD ZORIONAK!!!!!!!!!!!!!!!!!

:( tristura: ta bai, ni ere ya banuye lotara, nagola $\mathrm{KO}$, ta bihar klase... :( porque? porque? Jajajjaja

$=($ buaa, ze gaizki.. ni lokartu bai, biño denbora gutti $=($

:P mingaina kanpoan: maialeeen igotako argazki hori lehen eskuko informazioa? :P jajaj

:S gogaitua; zalantzatia; eszeptikoa: por cierto, barkatu orain kontestia, biño egon naiz aste guzia super liada ta tuenti ibiltzen nun mobillakin bakarrik, ta eztit uzten kontestia.. :S

$<3$ bihotza: Hoiek ttire galderak baldin bdakizu edozein gauz ere! san faborez!!! TQ $<3<3<3<3<3<3<3<3<3<3$ jajajajajajaj

WhatsAppen askoz gutxiagotan darabiltzate halako konbinazioak, aplikazioak irudi eginak ditu eta. Oso hiztun gutxik eta oso ikur osatu gutxi darabiltzate. Begi keinua eta musua dira nagusi. Ia beti mezuaren bukaeran irudikatzen dituzte, baita galdera edo harridura marken ondoan ere.

Muxitooo ;)

Muxutxoooooo ;))

Ueueueueueueuuu 7 terditann hann ikusikoo zaitutt berazzzz ? ;)

Paaaa ;)

Biharrr dokumentalaren aurkezpenaa dagoo ! ;)

Lagunekinn bertsosekatrekinnn ;)

Juerga ona botaaaaa, paaa :)))

Paaaa ;))

Esaldiaren bukaeran ez bada, oso-oso gutxitan darabiltzate ikurrok:

Ooo5oooo zeee ongiiii !!! ;) niiii bikainn guztiekinn egonnn taaa denaaa bikain orainn gauzatxoo batzukk eginn taaaa listo kalistoo ! Zu klaseann ?;)

Era berean, oso gutxitan darabiltzate ikur konbinazioak osagai hizkuntzazkoaren ordez. Haren osagarria izan ohi da irudi osatua.

H1: Kutxii sarreraaann?

$\mathrm{H} 2:$;) 
Mezu-igorlearen izenaren ondoan ere jartzen dute hiztun batzuek ikurra. Norberak edo taldeko beste hiztunen batek jarria izan daiteke. Igorleak bere burua nola ikusten duen adierazteko?, bere «ohiko» aldartea zein den ispilatzeko?, besteek nola ikustea nahi duen aditzen emateko?

IZENA1 ;): Nik geo atsaldian klase partikularrak ematea junhiet

IZENA2 :): Jooo nik ere nahi dot jajajajjaja

IZENA3 ;): Lagunekinn bertsosekatrekinnn ;)

\subsection{Emotikoiak}

Torresen arabera (2001), hiztunek, igorleek, ez dituzte emotikoiak erabiltzen bakar-bakarrik aldian aldiko poza eta tristura adierazteko; testuak pragmatikoki antolatzeko baliabideak ere badira emotikoiak. Enuntziatuak interpretatu eta desanbiguatzeko bitarteko ezinbestekoak dira, aurrez aurreko elkarrizketetan osagai paralinguistikoak (intonazioa) eta ahozkoak ez direnen maila berean.

Haizeaaaaaaaak bezalaaaa \$ Zeeerrrr moduzzz titiluaaaaaaaaaaaaa ??

Igorleak testuratu dituen noten irudiek solaslagunari ziurtatzen diote kantuaz ari dela (adibide honetan Ken zazpi taldearen «Haizea» kantuaren hasiera da), baina, aldi berean, solaslagunaren izenean oinarrituta (Haizea) «hitz-jolasa» egin nahi izan duela. Ludikotasunaren erakusgarri garbia.

Konparazioa egitea zilegi bada, esan daiteke alde honetatik emotikoiak antzerki-lan idatzietako «akotazio» modukoak direla. Mezu osoa nola interpretatu (eta deklamatu) behar duen esaten dio igorleak hartzaileari (aktoreari).

Idazkailuaren eta teklatu motaren arabera aukera diferenteak ditu hiztun idazleak. Gure lagineko hiztunek ia beti osagai linguistikoaren lagungarri darabiltzate emotikoiak, mezuaren interpretazioan laguntzeko. Gehienetan begitarte hauek erabiltzen dituzte:

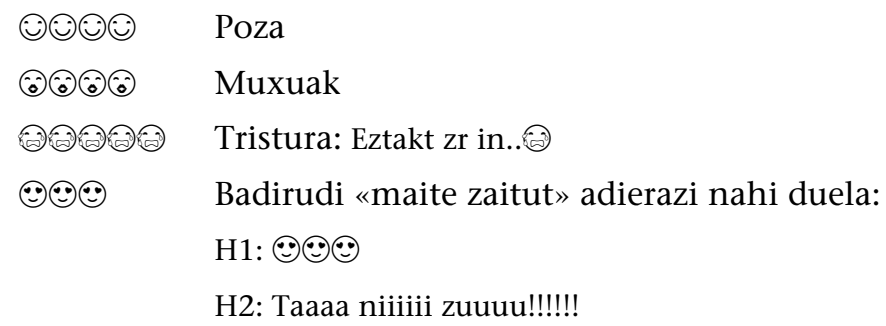

Aurpegiez gain, beste irudi batzuk ere baliagarriak gertatzen zaizkie. 
Beso indartsua:

$G_{0} G_{0} G_{0} G_{0} G_{0}$ oraiinn geldetukoo dut aberrr noizzz ditudann busakk Aix

Aix aixx ;)

Eskua, igorleak bere adostasuna adierazteko, dela behatz potoloa bakarrik altxatuz, dela garaipenaren ikurra eginez, erdiko bi behatzak altxatu:

H1: Mintza bihar entregatu ber da ez?

H2: Yes

H1:

H1: Geo oi jarri liburua dela bezela ta lixti

H2: Hoida jajaja

H3: 8 o

Txalo egiteko emotikoia, bai bakarrik bai antzeko desioa (zoriontzekoa) irudikatzeko beste emotikoi batzuekin batean:

Zorionak Aneee!! :

Bihotza, maitasuna adierazteko:

Politte daaaaa! $(-)$

Eguzkitako betaurrekoak dituen aurpegia oporrak adierazteko.

(2) buenoo tuu italiaraaa zoazelaa 20

Eta beste hainbat.

Emotikoien hiztegitik, nolabait esan, «alborakuntzaren sintaxira» igarotzen ari garela dirudi: gero eta gehiagotan ikusi ditugu emotikoi segidak. Hona elkarrizketa labur bat diogunaren adibide:

H1: Neskaaaaaaak

H1: Gainditu dot firsta $:-2 \cdot$

H2: ZORIONAKKK BA ANETXUUU!! gauzat gehio gaintik kendua jajaj

H1: Baaaaaai !!! Jajajajajaj

H1: Mileskeerrrrrr

H3: Anitaaaaaaaaa!!! ZOOORIONAAAKKKK!!! Ze ndooooooo!!!:-0) 
H4: Anetxikitxuuuu!!!! Zorionaaaaaaaaaaaaaak!!!! Lixtooo yaa indezuuu!!

H1: Jaajajajjaajajaa eskerrik askooooooo neskaak (-);0;

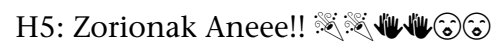

Emotikoein zerrenda luza daiteke, asko luzatu ere, baina gure lagineko hiztunek erabili dituzten emotikoi guztiak banaka aztertzeak ez luke zentzurik izango. Gainera, ez dago emotikoien kode finko itxirik, ez lotura bana-banakorik pentsatu ahal izateko «halako emotikoiak halako erreferentzia, esanahia, kontzeptua adierazten du». Sentimen bera irudi batek baino gehiagok irudika dezake. Eta, gainera, aplikazioek etengabe ugaritzen dituzte irudiak. Nolanahi dela ere, hiztunek gutxieneko oinarri bat konpartitu behar dute (Escandellen 2005, irudikapenak), bestela komunikazioa ezinezkoa litzateke.

Orain aipatu besterik egingo ez dugun beste gai bat ere bada tartean. Lan honen oinarrian dago hiztunak halako sentimen, emozio... adierazi nahi duelako aukeratzen duela hori irudika dezakeen emotikoia. Galdetzekoa da ea beti horrela den edo, jolasean-solasean, irudiekin topo egin eta ez ote dituen irudiak erabiltzen arrazoi estetiko, umoristiko eta antzekoengatik eta ez, nahitaez, barrenean duena kanporatzeko.

Emotikoi, irudi, ikono, sinboloen bitartezko adierazpena ez da hizkuntzaren artikulazio bikoitzarena bezalakoa. Idazkera alfabetikoa eta ikonikoa konbinatuta darabiltzate txatgileok, eta batak eta besteak balio diete adierazgarritasuna testura eramateko.

\section{Ondorioak}

Txat mintzidatziak ahozkoaren ezaugarriak baditu, baina ez dira guztiz soinu letraldatuak. Idazkerari dagokionaz gain, lexikoaren hautuan ere hiztunek txatetan darabiltzate ahoz erabiltzen ez dituzten hitz, esapide «adierazgarriak». Esate baterako, agurretako bokatibo, deikietan ikusi dugu hori.

Ildo beretik, ondorio zabalagoak ateratzeko neska-mutilen arteko corpus aberatsagoa beharko genuke eta, batez ere, mutilen arteko elkarrizketen corpusa. Ez dugu uste emozioak adierazteko neskek elkarren artean darabiltzaten adierazpide berberak erabiltzen dituztenik mutilek.

Beste alde batetik, berretsi behar dugu (Perez Gaztelu \& Zulaika 2014a, 2014b) plazaratua dugun ideia (Amonarrizen 2008 irizkide gara, hortaz): gazteen hizkera ez da bakarra, bat eta bera. Gazteek (ere) unean uneko egoerari egokitzen zaion hizkera erabiltzeko gaitasuna dutela erakutsia dago. Gaz- 
te(en) hizkeraz, singularrean, hitz egin baino egokiagoa da hizkerez, aldaera funtzionalez hitz egitea. Gure azterketen emaitzek agerian utzi dute ez dagoela aldarrikatzerik hainbatek baieztatu izan dutena; hots, lagunarteko hizkera behe- eta behe- eta erdi-mailako klaseek menderatzen duten erregistro bakarra dela.

Gazte(en) hizkerari egozten zaizkion ezaugarri batzuk (Ibarra 2011) ez dagozkie bakar-bakarrik gazteei. Helduagoek ere bai aurrez aurreko ahozko lagunarteko harremanetan bai Internet bidezkoetan erabiltzen ditugu, gutxiago edo gehiago, lan honetan sailkatu ditugun bi baliabide nagusietan bildutakoak: lexikoa, interjekzio-onomatopeiak, agurrak... Eta hemen jaso ez ditugun gehiago ere bai.

Gure azterketako euskal gazteak OBEko kodea eraikitzen ari dira auzolanean; bere idazkera dute, bere lexikoa, beren arteko harremanak hasi eta garatzekoa. Adierazgarritasunari dagokionez, euskal gazteek Tusónen (1996) funtzio autoespresiboaren, sintonia bilatzeko funtzioaren, eta Jakobsonen funtzio adierazkor, konatibo, fatiko eta poetikoaren erabilera sortzaile eta baliagarria egiten dutela ikusi dugu.

Euskaraz ere mintzatu-irudikatu-idazteko kodeak (alfabetikoa eta kode pikto-, ideografikoa) modu sortzaile eta adierazgarrian konbinatzen dituzte euskal gazteek. Bateratze horrek balio izan dezake hizkeren arteko ulermen ezak gainditzen laguntzeko.

Euskalki diferenteetako hiztunen arteko elkarrizketetan ez dugu ikusi, ez dute berariaz adierazi, ulertzeko zailtasunik zutenik. Asimilazio bustiduran eta hitz eta laburdura gutxi batzuetan ikusi ditugu desberdintasun handienak. Itxura batean, berezitasunak ez dira ulermenerako oztopoa eta, nolanahi dela ere, jokamolde bera dute (fonetismoak testuratu, agurtzeko modu antzekoak...) nahiz irtenbideak desberdinak izan, hain zuzen, darabilten hizkeragatik. Guztiarekin ere, azterkizun uzten dugu euskal gazteen txatetako «euskara batu idatzi lagunartekoa».

Adierazgarritasunaren azterketan ere - aitor dezagun, berriz ere-, gure ikerketa honek hutsune bat (gutxienez) badu, CS-ari arreta berezia eman behar zaio. Hutsune hori betetzen dihardugu.

\section{Erreferentzia bibliografikoak}

AMONARriz, Kike (2008), «Gazte hizkerak. Hizkera gazteak». BAT Soziolinguistika aldizkaria 68 (3): 167-183 or.

Azkarate, Miren (1990), «Euskal -garri vs. Latinezko -bilis bi balio desberdin». In E. Perez Gaztelu \& P. Urkizu (arg.), Patxi Altunari omenaldia. Donostia: Deustuko Unibertsitatea, 19-39 or.

- (1993), «-garri eta -kor atzizkien erabileraz». Berba 10.

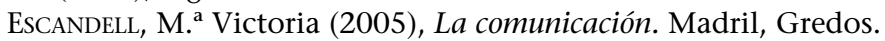


Gardner-Chloros, Penelope (2009), Code-switching. Cambridge University Press.

Herring, Susan C. (1996), «Introduction». In S. C. Herring (ed.), Computer-Mediated Communication. Linguistic, Social and Cross-Cultural Perspectives. Amsterdam / Philadelphia: John Benjamins, 1-10 or.

IBARRA, Orreaga (2008), "Apuntes sobre interferencia castellano-vasca en el lenguaje juvenil actual. Léxico, calcos y transferencia lingüística», Oihenart 23: 219-240 or.

- (2011), Nafar euskaldun gazteen ahozko diskurtsoa, Nafarroako Unibertsitate Publikoa.

IVERSON, Gregory K. \& Oñederra, Miren Lourdes (1985), «On Basque Palatalization», Folia Linguistica 19: 51-61 or.

OñEDERRA, Miren Lourdes (1990), Euskal fonologia. Palatizazioa, asimilizazioa eta hots sinbolismoa. UPV/EHU.

OyHARÇABAL, Beñat (2001), «Kor atzizkiaz». In J.M. Makatzaga \& B. Oyharçabal (edit.) Euskal gramatika eta literaturari buruzko ikerketak XXI. mendearen atarian. Iker 14 (1): 357-383 or.

Perez Gaztelu, Elixabete \& Zulaika IjurKo, Esther (2014a), «Comunicarse escriblando en las redes». $K+$ e. Komunikazio eremuak / Espacios de comunicación. IV Nazioarteko Biltzarra Komunikazioaren Ikerkuntzarako Espainiar Elkartea. IV. Congreso internacional de la Asociación Española de Investigación de la Comunicación: 765-782. [Revista de la Asociación Española de Investigación de la Comunicación (RAEIC) 1: 117-128 or.].

- (2014b), «Gzteak lgnrtn idztn: Mintzidatzien antolamendua». In I. Aduriz \& R. Urizar (ed.), Euskal hizkuntzalaritzaren egungo zenbait ikerlerro. Hizkuntzalari euskaldunen I. topaketa. Bilbo: Udako Euskal Unibertsitatea, 111-133 or.

Porroche BALlesteros, Margarita (2015), «Sobre la manifestación del significado expresivo en español». In D. Serrano-Dolader \& M. Porroche Ballesteros, M. ${ }^{a}$ Martín Zorraquino (ed.), Aspectos de la subjetividad en el lenguaje. Zaragoza: Institución Fernando el Católico, 187-205 or.

Rodrigo Alsina, Miguel $\left(1989,1995_{2}\right)$, Los modelos de la comunicación. Madril: Tecnos.

TORRES I VilatarsanA, Marta (1999), «Els xats: entre l'oralitat i I'escriptura», Els Marges 65: $113-126$ or.

- (2001), «Funciones pragmáticas de los emoticonos en la comunicación mediatizada por ordenador», Revista TEXTOS de la CiberSociedad, 1. Temática Variada. http://www.cibersociedad.net/textos/articulo.php?art=24 [azken ikustaldia: 2015eko irailaren 30ean]

TusóN, Jesús (1996), «Lenguaje, comunicación y persuasión». In J. R. Zubiaur \& I. Beti (ed.), Mitos, teorías y aspectos del lenguaje. Donostia: Deustuko Unibertsitatea, 71-82 or.

VINTRÓ, Eulàlia (2002), «El movimiento sofístico. El nacimiento de la retórica», Bitarte: 26: 5-22 or.

Watzlawick, Paul, Bavelas, Janet \& Jackson, Don D. (1967), Pragmatics of Human Communication [1985, Teoría de la comunicación humana. Herder]. http://primeravocal. org/wp-content/uploads/2011/05/Watzlawick-Paul-Teoria-De-La-ComunicacionHumana3.pdf [azken ikustaldia: 2015eko irailaren 30ean]

Zamorano Aguilar, A., Calero Vaquera, M.L. \& López Quero, S. (2004), «Foros de debate vs. otros discursos electrónicos», Español Actual, 82: 53-75 or. 